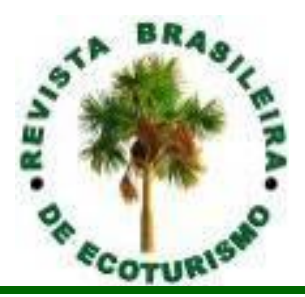

\title{
Turismo e esgoto domésticos na Ilha Grande (RJ): uma análise exploratória nas praias de Abraão e Aventureiro
}

\section{Tourism and domestic sewage in Ilha Grande island (RJ, Brazil): exploratory analysis on the beaches of Abraão and Aventureiro}

Débora Mury Alves Chueiri, Rafael Angelo Fortunato

RESUMO: Dentre os inúmeros impactos negativos ao ambiente marinho, destaca-se a falta de saneamento básico, em que muitas vezes os esgotos domésticos são lançados em córregos rios e mares. Esse é o caso da llha Grande, no estado do Rio de Janeiro. Esse estudo partiu da premissa de que o grande fluxo de pessoas relacionado ao turismo e associado à inadequação dos serviços básicos de tratamento de esgoto, polui e provoca impactos negativos ao ambiente marinho, acarretando problemas para 0 desenvolvimento e manutenção do turismo como atividade econômica. $O$ objetivo foi verificar se existem visões diferentes em relação à poluição por esgoto doméstico e seus impactos nas praias de Abraão e do Aventureiro na Ilha Grande. Foram aplicadas entrevistas semiestruturadas realizadas com os moradores, turistas e o gestor do órgão ambiental. Os resultados obtidos a partir da análise exploratória apontam que a praia de Abraão apresenta um desenvolvimento desordenado do turismo com indícios de poluição no ambiente marinho, em decorrência da saturação da capacidade de carga de turistas e a praia do Aventureiro, mesmo sendo uma Reserva de Desenvolvimento Sustentável, com controle da entrada de turistas, já mostra evidências de poluição. O turismo aparece como sinônimo de tensão e, ao mesmo tempo, de lazer e oportunidade de empregos para a Ilha Grande. É evidente a necessidade de um plano de gestão costeira em ambas as praias para que haja um turismo ordenado e sustentável na Ilha Grande.

PALAVRAS-CHAVE: Turismo; Gestão Costeira; Esgoto Doméstico. 
ABSTRACT: The lack of basic sanitation has many negative impacts on the marine environment because domestic sewage is often discharged into rivers and sea without prior treatment. This is the case of Ilha Grande, in the state of Rio de Janeiro. This study was based on the premise that the large growing flow of people related to tourism and associated with inadequate basic sewage treatment service causes negative impacts on the marine environment, causing problems for the development and maintenance of the economy of Tourism. The main objective of this study was to verify if there are different points of views regarding the domestic sewage pollution and its negative impacts on the beaches of Abraão and Aventureiro. Semi structured interviews were conducted with residents, tourists, and environmental managers. The results obtained from the exploratory analysis indicate that the Abraão beach has a disorderly development of the tourism economy with signs of pollution in the marine environment, due to the saturation of the carrying capacity of tourists. The beach of Aventureiro, even though it is a Sustainable Development Reserve, with control of the entry of tourists, already shows evidence of pollution. The tourism in Ilha Grande appears as a synonym of tension and, at the same time, leisure, and opportunity for works. The need for a coastal management plan on both beaches is evident in order to have sustainable tourism on Ilha Grande.

KEYWORDS: Tourism; Coastal Management; Domestic Sewage

\section{Introdução}

A sociedade brasileira apresenta um cenário muito preocupante quando se refere à área ambiental. Dentre as mais variáveis causas desse cenário, destaca-se a falta de saneamento básico, que se reflete tanto a nível local como nacional e causa impactos negativos ao meio ambiente, provenientes do despejo de esgotos domésticos sem um tratamento prévio ou eficiente. Esses são lançados muitas vezes diretamente em córregos, rios e mares.

A qualidade das águas costeiras tem sofrido um intenso processo de degradação pelo lançamento de esgotos, que escoam para as praias sem qualquer tratamento prévio, seja em lançamentos diretos ou pelas redes de drenagem pluviais.

Dentro desse contexto de falta de infraestrutura básica para atender toda população brasileira, a zona costeira e especificamente o ambiente marinho torna-se mais vulnerável pela diversidade e fragilidade dos ecossistemas.

Um exemplo desse cenário é a llha Grande, que pertence ao município de Angra dos Reis, localizada no extremo oeste do Estado do Rio de Janeiro (INEA - INSTITUTO ESTADUAL DO AMBIENTE, 2011). Dentre as mais de 300 ilhas da baía, para a realização dessa pesquisa, foi selecionada a Ilha Grande, por receber o maior fluxo de turistas na Baía da Ilha Grande e na última década, por esse motivo, ter aumentando o número de moradores em busca de oportunidades de trabalho voltadas para 0 turismo. 
Esta llha abrange o Parque Estadual da llha Grande e possui quatro diferentes categorias de unidades de conservação em seu território, sendo fundamental para a preservação do ambiente marinho. Com a implantação das Unidades de Conservação, algumas leis ambientais foram impostas proibindo atividades corriqueiras entre as comunidades locais como: a agricultura, a pesca, e a caça. Com isso, a principal economia passou a ser o turismo, atividade econômica permitida em algumas áreas da llha, conforme estipulado pelas distintas áreas de zoneamento.

Se por um lado, o turismo contribui economicamente para o sustento dos habitantes da llha, por outro, essa economia polui o ambiente marinho. Tal processo pode ser considerado uma ameaça à manutenção da qualidade ambiental e de vida do local, podendo significar inclusive a própria desvalorização turística.

Parte-se da premissa de que o grande fluxo de turistas associado à inadequação dos serviços básicos de tratamento de esgoto, polui e provoca impactos negativos no ambiente marinho, acarretando problemas para o desenvolvimento e manutenção do próprio turismo como atividade econômica.

O objetivo da pesquisa foi verificar se existem visões diferentes a respeito da poluição gerada pelo esgoto doméstico nas praias de Abraão e Aventureiro por parte dos entrevistados: turistas, moradores e gestor. Essas duas praias foram escolhidas por terem características distintas, como: a quantidade de fluxo turístico, infraestrutura turística, diferentes questões legislativas por terem categorias distintas de Unidade de Conservação e pela estrutura de saneamento básico.

Essa pesquisa é composta por três etapas, procedimento metodológico, discussão da relação entre gestão costeira, esgotos domésticos e turismo na llha Grande e, em seguida, reflete-se sobre a poluição por esgotos domésticos na praia de Abraão e do Aventureiro.

\section{Procedimentos metodológicos}

O procedimento metodológico utilizado para o desenvolvimento desse estudo foi a perspectiva qualitativa, em que foram utilizadas as técnicas de levantamento bibliográfico, de dados primários pautados em entrevistas semiestruturadas com os moradores, turistas e gestor do Parque, coleta de dados secundários da área ambiental e turística e a observação direta.

Foram aplicadas entrevistas semiestruturadas para moradores e turistas, abordados aleatoriamente em diferentes dias no período de alta temporada nas praias do Aventureiro e Abraão. Havia questões voltadas à compreensão da visão sobre os esgotos lançados no ambiente. Elas foram posteriormente transcritas. Partiu-se das seguintes perguntas: Quais são os impactos negativos provocados pelo desenvolvimento do turismo em termos de gestão, pelo o que você observa nesta praia, você acha que o turismo 
traz algum tipo de problema? O que você pensa sobre o despejo de líquidos, restos de comida, dos líquidos de banheiro e cozinha?

O primeiro campo foi do dia 3 até 17 de dezembro/2018 na Praia de Abraão, totalizando 42 entrevistas e do dia 17 até 22 dezembro /2018 na Praia do Aventureiro, totalizando 16 entrevistas. No segundo campo, do dia 20 a 27 de janeiro/2019 na Praia do Aventureiro, totalizando 39 entrevistas e do dia 27 a 30 de janeiro/2019 na Praia de Abraão, totalizando 7 entrevistas.

Além das entrevistas semiestruturadas, para compreender a relação desses atores com o mar e o modo de vida na dinâmica da alta temporada turística, foram realizadas conversas informais, que possibilitou estabelecer um vínculo de confiança. Essas vivências e as observações diretas foram anotadas no diário de campo.

\section{Gestão costeira, esgoto doméstico e o turismo na Ilha Grande}

O Brasil é conhecido pelas suas paisagens naturais ao longo de mais de 8000 km de litoral (IBGE - Instituto Brasileiro De Geografia E Estatística, 2011), com uma zona costeira, composta por uma grande diversidade de ecossistemas marinhos como dunas, recifes de corais, baías, estuários, lagoas e manguezais (DIEGUES, 1999). A zona costeira teve sua ocupação intensificada nas últimas décadas devido a um processo rápido de urbanização, desde a década de 1960, principalmente por causa da industrialização, produção de petróleo e gás natural, pesca e turismo (IBGEINSTITUTO BRASILEIRO DE GEOGRAFIA E ESTATISTICA, 2011; MORAES, 1999), causando diversos impactos negativos ao meio ambiente.

Com o propósito de preservar a zona costeira, a constituição federal define essa área como patrimônio nacional e cria diretrizes para o seu gerenciamento. Na perspectiva de (Polette et al., 2000), o gerenciamento costeiro foi constituído para solucionar conflitos ao longo da área costeira, em decorrência dos diversos usos, para redução dos impactos e pôr fim a delimitação da utilização dos recursos costeiros. O objetivo da gestão costeira é o planejamento físico e o ordenamento do uso do solo e das águas costeiras (MEDEIROS; MAIA; PEREIRA DE ARAÚJO, 2016; NICOLODI; ZAMBONI; BARROSO, 2009).

A meta da gestão costeira deve ser "(...) melhorar a qualidade de vida das comunidades humanas que dependem dos recursos costeiros levando em consideração a manutenção da diversidade biológica e a produtividade dos ecossistemas costeiros" (POLETTE; SILVA, 2003, p.28 ).

A gestão costeira torna-se uma questão central que visa unir o desenvolvimento econômico, protegendo e garantindo os recursos naturais para gerações futuras, incluindo o bem-estar da população. Ela tem como resultado a promoção de ações para minimizar os impactos negativos envolvendo a comunidade nas tomadas de decisões.

Planos de ações que objetivam a melhoria da gestão da zona costeira no Brasil são abundantes, incluindo os Planos Estaduais de Gerenciamento Costeiro. Tais planos são considerados uma importante 
ferramenta para a proteção dos ecossistemas, pois propõem programas, linhas de atuação e planos de ação que visam a organizar os usos e as atividades verificados na zona costeira do Estado.

Dentre as atividades econômicas exploradas na zona costeira, incluindo as ilhas, o setor turístico vem se expandindo como a principal fonte de renda, justamente por terem seus ecossistemas ainda preservados, fator motivador para o Brasil vender roteiros de paisagens naturais para turistas do mundo todo.

As ilhas são consideradas parte da zona costeira e possuem grande valor ambiental pela inegável riqueza de seus ecossistemas. Elas são protegidas no ordenamento jurídico, Lei 9.985 , de 18.07 .2000 e destinadas prioritariamente à proteção da natureza, em decorrência do valor ecossistêmico e de vulnerabilidade, porém com a ocupação e a visitação controladas, limitadas ou até mesmo vedadas.

O desenvolvimento econômico de boa parte das llhas brasileiras tem sido baseado no setor turístico. Segundo (Briguglio; Briguglio, 1996), essa dependência é muitas vezes incentivada pelos seus governantes, que, perceberem na atividade uma forma de desenvolver e potencializar a economia do território insular, desconsideram aspectos como: valores das culturas locais ou leis ambientais e de uso do solo e passam a permitir o investimento externo na implantação de empreendimentos turísticos.

Essa questão provoca cada vez mais o aumento do fluxo turístico e da arrecadação, proveniente dos meios de hospedagem, aumento de portos de acesso e fluxo náutico. Esse cenário acarreta diversos impactos negativos ao meio ambiente inclusive a alteração da paisagem natural.

Segundo Silva Junior et al., (2016), as diversas atividades recreativas do turismo causam possíveis impactos negativos ao meio ambiente, especificamente nos processos ecológicos, alterando a qualidade da paisagem. No estudo realizado no Parque Estadual da Ilha de Anchieta, Ubatuba, sobre a qualidade visual da paisagem, teve como resultado negativo os locais com fácil acesso para os turistas, em que o quesito qualidade visual foi mais baixo do que as áreas de difícil acesso.

A llha de Florianópolis também é um exemplo do declínio da qualidade ambiental, ela apresenta uma vasta diversidade de ecossistemas marinhos aliados a urbanização intensificada e uma massiva exploração do turismo. O resultado dessa combinação foi a alteração das praias estudadas, em que as paisagens naturais foram modificadas de alguma forma, reduzindo a atratividade cênica, por causado alto potencial de poluição sanitária, sendo necessário ações de planejamento e gestão para minimizar os danos e/ ou restaurar os ambientes costeiros (OLIVEIRA et al., 2016).

Lins-De-Barros; Mansur, 2018 também citam como problema crítico a poluição da zona costeira por esgoto doméstico e questões sobre pressão turística, em uma análise crítica sobre gestão costeira integrada do estudo de caso da Região dos Lagos, no estado do Rio de Janeiro. 
E possível afirmar que a alteração das paisagens, não ocorrem somente pela popularidade de seu roteiro, porém também por falta de infraestrutura básica, como uma estação de tratamento de esgoto.

Considerando que as zonas costeiras são áreas de alta vulnerabilidade e onde concentra a maior biodiversidade, são nesses espaços aquáticos onde convergem as maiores preocupações quanto à preservação dos seus ecossistemas. Dentre as inúmeras preocupações existem o despejo de esgoto doméstico no ambiente marinho, que muitas vezes é lançado com uma carga grande de matéria orgânica e outros poluentes orgânicos e inorgânicos, sendo causadores da redução e fragmentação de habitats, reconhecidas como principais causas da perda da biodiversidade (WILSON, 1999).

Ambas as situações, pressões do turismo e lançamento do esgoto doméstico in loco, tem sido observado na llha Grande, como fatores negativos que implicam na alteração das paisagens. O diagnóstico da Baia da Ilha Grande (Johnsson; Ikemoto, 2015), afirma que os impactos negativos da eutrofização costeira ocorrem pelo excesso de nutrientes na água, onde tornam-se mais intensos em ambientes de circulação restrita, tais como as enseadas, que é onde a praia de Abraão está inserida, a principal praia da Ilha Grande.

Para a preservação desse espaço insular de grande relevância natural e cultural, foram implantados na llha Grande quatro tipos de Unidades de Conservação com papéis complementares entre si (Tabela 1), tendo o mesmo objetivo: o de proteger e preservar os ecossistemas.

Tabela 1:Os tipos de Unidades de Conservação na Ilha Grande.

Table 1: The types of Conservation Units on Ilha Grande.

\begin{tabular}{|l|l|l|}
\hline $\begin{array}{l}\text { Parque Estadual da Ilha Grande } \\
\text { (PEIG). }\end{array}$ & Criado em 1971 & $\begin{array}{l}\text { Principal Unidade de Conservação, } \\
\text { abrange cerca de 62\% da ilha. Dividia } \\
\text { em áreas de zoneamento, onde cada } \\
\text { uma delimita o uso da terra. }\end{array}$ \\
\hline $\begin{array}{l}\text { Reserva Biológica da Praia do Sul } \\
\text { (ReBio). }\end{array}$ & Criado em 1981 & $\begin{array}{l}\text { Unidade de Proteção Integral, são } \\
\text { permitidos estudos científicos e a } \\
\text { passagem de Turistas que fazem a } \\
\text { volta na Ilha Grande, com autorização } \\
\text { prévia do INEA. }\end{array}$ \\
\hline $\begin{array}{l}\text { Reserva de Desenvolvimento } \\
\text { Sustentável (RDS), Aventureiro, } \\
\text { que inclui o Parque Estadual } \\
\text { Marinho do Aventureiro (PEMA). }\end{array}$ & $\begin{array}{l}\text { Até 2014 fazia parte da ReBio e foi } \\
\text { recategorização pela Lei no 6.793. A } \\
\text { RDS do Aventureiro ainda não possui } \\
\text { o plano de manejo, porém é proibido } \\
\text { construções e pesca comercial. }\end{array}$ \\
\hline $\begin{array}{l}\text { Área de Proteção Ambiental } \\
\text { (APA) de Tamoios. }\end{array}$ & Criado em 1982 & $\begin{array}{l}\text { Disciplina o uso da terra onde a lei } \\
\text { faculta alguma espécie de ocupação } \\
\text { humana. }\end{array}$ \\
\hline
\end{tabular}

Fonte: Mendonça e Moraes, (2011), adaptado pela autora (2019).

Source: Mendonça and Moraes, (2011), adapted by the author (2019).

Segue na Figura 1 a localização das Unidades de Conservação incluindo os núcleos populacionais da RDS do Aventureiro e da Villa de Abraão, nas quais foram feitas as entrevistas. 


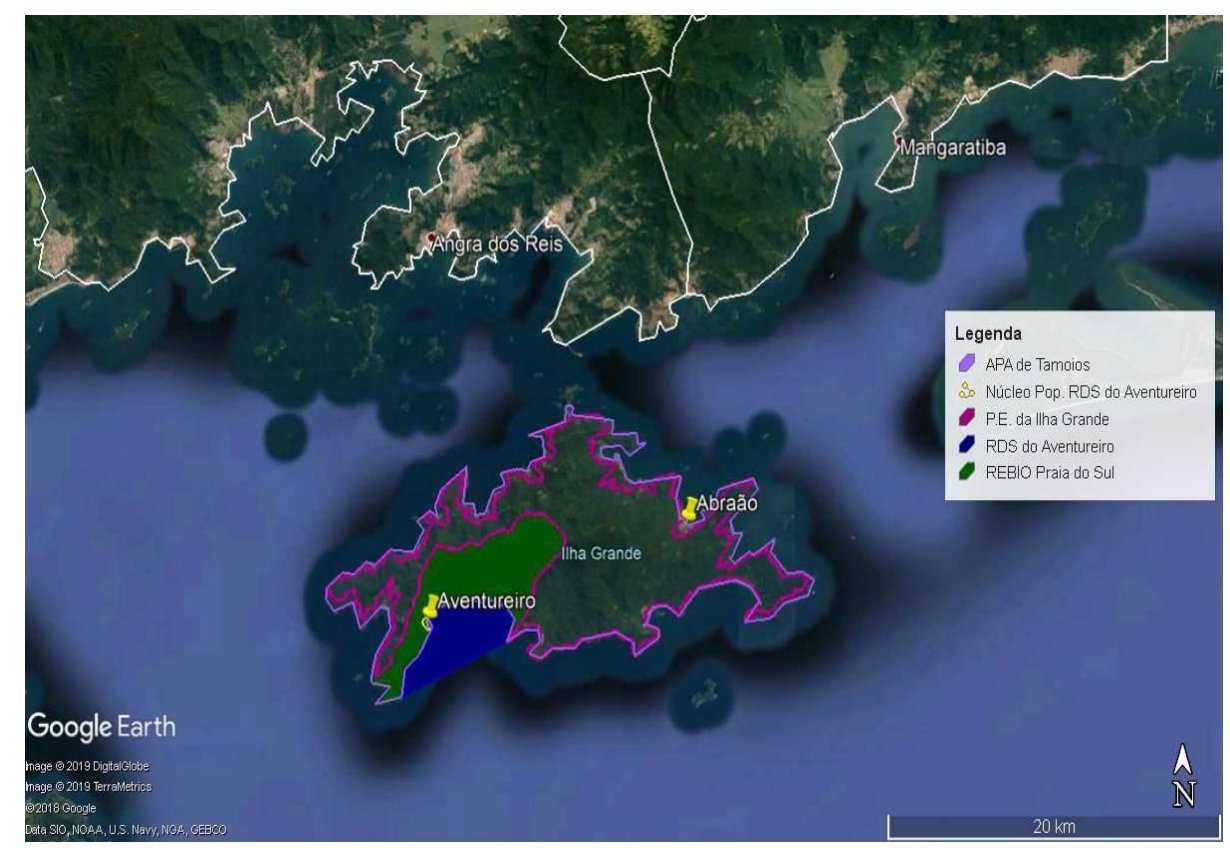

Figura 1: Mapa com as divisões da Unidades de Conservação da Ilha Grande. Figure 1: Map with divisions of the llha Grande Conservation Units.

Fonte: elaborado pelos autores (2019).

Source: elaborated by the authors (2019).

Com a implantação das Unidades de Conservação, algumas atividades rotineiras da comunidade local foram proibidas, acarretando gradualmente na redução das atividades tradicionais, como a pesca e a agricultura, para dar lugar à economia do turismo (WUNDER, 2006).

O desenvolvimento do turismo na llha Grande pode ser atribuído, além da implantação das Unidades de Conservação, a algumas questões a nível nacional e regional, como a construção da rodovia Rio-Santos (BR101), na década de 70, que favoreceu o acesso e a urbanização, o Projeto Turis (Plano de Aperfeiçoamento Turístico) do Instituto Brasileiro de Turismo EMBRATUR, também na década de 1970 e o término das atividades carcerárias. Esses fatos, principalmente a implosão do presídio, trouxeram um aumento expressivo no fluxo turístico e consequentemente um acelerado crescimento na infraestrutura para atender a economia do turismo.

Wunder, 2006 analisa o crescimento do turismo como um processo negativo, em que ocasionou problemas de congestionamento turístico, ultrapassando a capacidade de suporte da llha, na Vila de Abraão. O mesmo autor ressalta que o lixo e a poluição das praias aumentam com o número de visitantes.

Para a realização deste artigo, foram escolhidas duas praias para a análise exploratória sobre o poluente esgoto doméstico: a praia de Abraão situada na Villa de Abraão, de fácil acesso, e a praia do Aventureiro, localizada na região oceânica da ilha, de difícil acesso.

Uma parte da Vila de Abraão está inserida na APA Tamoios, administrada pela prefeitura de Angra dos Reis e a outra parte, pela PEIG, administrado pelo INEA. Segundo o Decreto n-20.172, de 01 de julho de 
1994, a APA de Tamoios é dividida em quatro zoneamentos, dentre elas a Zona de Ocupação Controlada, que contempla uma porção da vila de Abraão. Nesta região é permitido o desenvolvimento do turismo e construções com certas restrições e licenciamento ambiental prévio.

A Vila de Abraão é o espaço da llha mais povoado e recebe a maior parte dos turistas, tem a cadeia produtiva do turismo mais estruturada, quando comparado ao restante das praias na Ilha. Esta abriga as sedes da subprefeitura e dos órgãos de Meio Ambiente, por isso, chamada de "capital econômica" da llha.

Segundo dados da Fundação de Turismo de Angra dos Reis, foi estimado um fluxo turístico de um milhão trezentos e trinta e dois turistas por ano. Esses dados são tabulados a partir da média de lotação das embarcações anuais de traslados, passeios e navios, assim como a quantidade de pessoas nos meios de hospedagem, multiplicando 0 percentual de ocupação pela quantidade de leitos disponíveis vezes 12 meses (comunicação pessoal, Pires, A., 7 de Jun. 2019). A facilidade de acesso à vila também faz com que o número de turistas seja mais elevado que no restante da ilha, e isso juntamente por seus atrativos naturais: cachoeiras, diversas praias e trilhas de variados níveis de dificuldade, tornando esse local, um atrativo único. Existem também, na vila, ruínas de antigas construções, da época do império, como as ruínas do lazareto, que recebiam os enfermos que chegavam ao país, onde no século $X X$, foi transformado em prisão, e passou a receber presos políticos (ARAUJO et all., 2005).

A outra praia escolhida a RDS do Aventureiro, localizada na face oceânica da Ilha, Sul, que conta apenas com uma pequena vila de pescadores de aproximadamente 100 habitantes (MENDONÇA; MORAES, 2011). Em 2018, apresentou o fluxo turístico anual, segundo a Fundação de Turismo de Angra dos Reis, de 3.021 turistas (comunicação pessoal, Pires, A., 7 de Jun. 2019). Sua localização, voltada para mar aberto, é um grande limitador natural, pois quando entram as frentes frias, o mar fica "grosso", conforme termo utilizado pelos locais, e o transporte marítimo se torna impraticável.

A pequena comunidade teve seu sistema de manutenção mantido por muitos anos através da pesca, caça eventual na floresta e agricultura doméstica especificamente para a produção de farinha de mandioca (VILAÇA; MAIA, 2006). Em 1981, foi criada a Reserva Biológica (ReBio) da Praia do Sul, onde englobava a vila do Aventureiro, gerando um intenso conflito socioambiental na região, já que a ReBio restringe qualquer tipo de atividade em suas áreas, não respeitando os costumes e tradições da comunidade que havia ali, sofrendo uma série de restrições, em decorrência das leis ambientais, ao seu modo de vida e chegando a sofrer ameaças de expulsão (MENDONÇA; FONTOURA, 2010).

Mesmo com a implementação da ReBio, o povo do Aventureiro continuou a exercer suas atividades e a desenvolver o turismo na praia (MENDONÇA; FONTOURA, 2010). Inúmeros casos de conflitos entre os moradores e agentes do governo foram registrados, mas o mais evidente foi 
o que ocorreu no período de carnaval do ano de 2006, quando a força tarefa da prefeitura de Angra dos Reis impediu que os turistas se instalassem nos campings montados nos quintais das casas dos caiçaras, o que gerou uma grave crise entre os moradores, já que em sua maioria, dependem quase que exclusivamente da renda proveniente do turismo para sobreviver. (MENDONÇA; MORAES, 2011).

Depois de muito conflito, em maio de 2014, foi publicada uma Lei $n^{\circ}$ 6.793, de 28 de maio de 2014, reduzindo em 2,7\% a área da ReBio, retirando a Vila do Aventureiro de sua demarcação, e assim, passando a ser reconhecida como RDS permitindo que seus moradores pudessem trabalhar com o turismo de maneira legal, além de poderem retomar as atividades de pesca, para consumo da própria comunidade na região.

A Praia do Aventureiro conta ainda com uma concessão para o recebimento de turistas, dada por: a prefeitura de Angra dos Reis, pelo Ministério Público do Estado do Rio de Janeiro, a Procuradoria Geral do Estado do Rio de Janeiro, a Fundação Estadual de Engenharia do Meio Ambiente, hoje INEA, e a Associação de Moradores e Amigos do Aventureiro, atualmente desativada, que em conjunto elaboraram um plano de carga, o qual estipula um limite de 560 pessoas por dia na praia, e um máximo de 18 campings em seu território (MENDONÇA; MORAES, 2011).

Para ir à praia do Aventureiro é necessário retirar uma pulseira de identificação em Angra dos Reis, na Turisangra, responsável por esse controle. Segundo relatos de moradores, em janeiro de 2019, tiveram aproximadamente 3 mil pessoas na virada do ano novo, muitos sem a pulseira de controle, o que é visível a ausência da fiscalização por porta de prefeitura de Angra dos Reis. Esse número acabou excedendo a capacidade estrutural, deixando marcas de poluição pela areia.

A partir disso, inicia-se uma nova configuração social, um novo processo de desenvolvimento econômico e uma alteração na paisagem, em que a apropriação e exploração da natureza e da sociedade local intensificase para atender ao desenvolvimento do turismo.

Wunder (2006) analisa o turismo na praia do Aventureiro, antes de se tornar uma RDS, e relata o cenário da infraestrutura turística ainda caseira, com campings no quintal da casa dos moradores, venda de almoço (prato feito) na cozinha de suas casas e transporte feito por embarcações de pesca.

Já Mendonça e Fontoura (2010) acrescentam, em sua análise posterior ao Wander, o surgimento dos aluguéis de pequenos quartos, sem muita estrutura, por ser uma RDS, que consistem em algumas proibições como construções em geral (casas, meio de hospedagens e restaurantes).

É notório que essa praia teve pequenas mudanças quanto à organização produtiva do turismo. Atualmente, existem mais barcos destinados a categoria de transporte para turismo, locais com wifi e com sinal de telefone. Com isso, ocorreu uma procura pelo lugar, acarretando o aumento do fluxo de turistas, uma vez que a legislação ambiental se tornou 
menos restritiva devido à mudança de categoria de Unidade de Conservação.

É possível analisar que essas transformações legislativa e econômica trouxeram à população outra realidade de vida, uma mudança em suas rotinas, principalmente, no período de alta temporada, em que substituíram a pesca e a agricultura de queimada, atividades que demandam maior tempo e esforço físico com baixo retorno financeiro, pelo turismo.

\section{Ilha Grande e os esgotos domésticos nas praias de Abraão e Aventureiro}

$\mathrm{Na}$ última década, o turismo na llha Grande teve um crescimento desenfreado, atraindo um grande fluxo de turistas e, consequentemente, de novos moradores em busca de oportunidades de emprego na alta temporada. Sendo assim, ocorreu uma rápida ocupação urbana e expansão imobiliária, novas moradias foram construídas para os trabalhadores, casas de veraneio e locais que vendem serviços para atender os turistas.

Dados secundários relatam que a ilha tem uma grande disponibilidade hídrica, porém, não possui capacidade para tratar a demanda de esgotos, provenientes do grande fluxo de turistas, visitantes e moradores (INEA, 2011).

Muitas construções não são integradas com a rede de saneamento básico, incluindo casas mais antigas, construídas antes do turismo chegar à Ilha. Foi possível constatar que algumas casas com capacidade para abrigar cinco pessoas, atualmente alojam 30 . O gestor $^{1}$ do Parque ressalta que essa questão "vai colapsar o sistema de esgoto, são várias casas que não estão interligadas na rede de esgoto", relata o gestor.

A questão dos esgotos não impacta apenas a qualidade da água, mas também o turismo visualmente. E acrescenta "é necessário investimento para ampliar a estação de tratamento de esgoto".

A qualidade da água da enseada da Vila de Abrão, entre os anos de 2012 até 2015, tornou-se imprópria para banho (INEA, 2008 -2015). As análises biológicas realizadas pelo INEA, enterococos, que é um dos parâmetros analisados para balneabilidade do mar, apontam uma variação de 679 até $4.884 \mathrm{NMP} / 100 \mathrm{ml}$. Esse valor ultrapassa os valores da resolução do Conselho Nacional do Meio Ambiente - CONAMA no 274/2000, o que é possível afirmar que a concentração de coliformes fecais é alta.

A Estação de Tratamento de Esgoto da Ilha Grande, pertencente ao Serviço Autônomo de Águas e Esgoto beneficia 7mil e 500 pessoas por ano, sendo que o fluxo turístico é de 360 mil visitantes por ano, dos quais $114 \mathrm{mil}$ pernoitam, tendo o maior fluxo nos meses de dezembro, janeiro e fevereiro (INEA, 2011). Isso significa que a ETE, não consegue tratar a demanda nos picos de alta temporada. Segundo o relato do gestor, o INEA já autuou diversas vezes o Serviço Autônomo de Água e Esgoto (Saae), responsável pelo tratamento de esgoto da llha, e o problema persiste, por falta de verba para a obra. 
Acrescenta o gestor que a solução não é multar a Saae, pois o problema é a falta de verba para investir na melhoria da infraestrutura e relata ainda que as obras de saneamento, drenagem e urbanização na Vila do Abraão, financiado pelo Banco Interamericano de Desenvolvimento, ligado ao do Programa Nacional de Desenvolvimento do Turismo, teve o início de sua obra interrompida por questões políticas e financeiras, deixando os materiais entulhados nas proximidades da ETE.

Como consequência da ineficiência do serviço de tratamento de esgoto e a falta de gestão pública, uma parcela dos esgotos é lançada no corpo d'água causando impactos negativos à biodiversidade e alterando a qualidade da água. Os esgotos são carregados de altos índices de substâncias orgânicas, ricas em carbono, nitrogênio e fósforo, podem ultrapassar a capacidade de mineração excedendo a capacidade de degradação microbiana, ela tende a se acumular no ambiente (MARQUES JR.; MORAES DE; MAURAT, 2009).

Creed e Oliveira, (2007) em seu estudo metodológico de análise de impacto ambiental, apontam a problemática de descarga de esgoto para a face norte da llha Grande, onde está localizada a Villa de Abraão.

Apesar de ser evidente o declínio da qualidade do ambiente marinho, tanto por parte da literatura quanto pela observação direta, alguns moradores dizem que o mesmo pode ser utilizado pelos turistas.

Esse fato demonstra uma contradição em relação aos dados de balneabilidade, os quais afirmam que a área é imprópria para banho, essa informação é tratada de forma distinta por diferentes informantes. Aqueles que possuem empreendimento próximo à praia de Abraão tendem a dizer que a água é boa para mergulho, pois sabem que a poluição do mar pode reduzir o consumo dos turistas nos restaurantes. Outros moradores afirmam que a água é suja e que os rios estão poluídos, eles relatam falta de saneamento básico e dizem que alguns moradores jogam seus esgotos direto na barra e acrescentam que, quando a ilha está muito cheia, a estação de tratamento "abre e manda todo esgoto direto para o mar".

Ao questionar ao INEA porque a falta de placas sinalizando água imprópria para banho, foi informado que os próprios moradores retiram, pois, alguns comerciantes acreditam que com a sinalização pode reduzir 0 consumo dos turistas nos seus empreendimentos.

A dona de hostel, situado na parte central da llha, explica que em períodos de grande fluxo de turistas há transbordamentos, com o esgoto passando a escoar em valas a céu aberto. Alguns locais lançam seus dejetos diretamente nos córregos que escoam direto para o mar.

No mês de dezembro de 2019 foi feita uma denúncia para o INEA relatando que o rio estava com uma coloração branca e azul (Figura 2). 


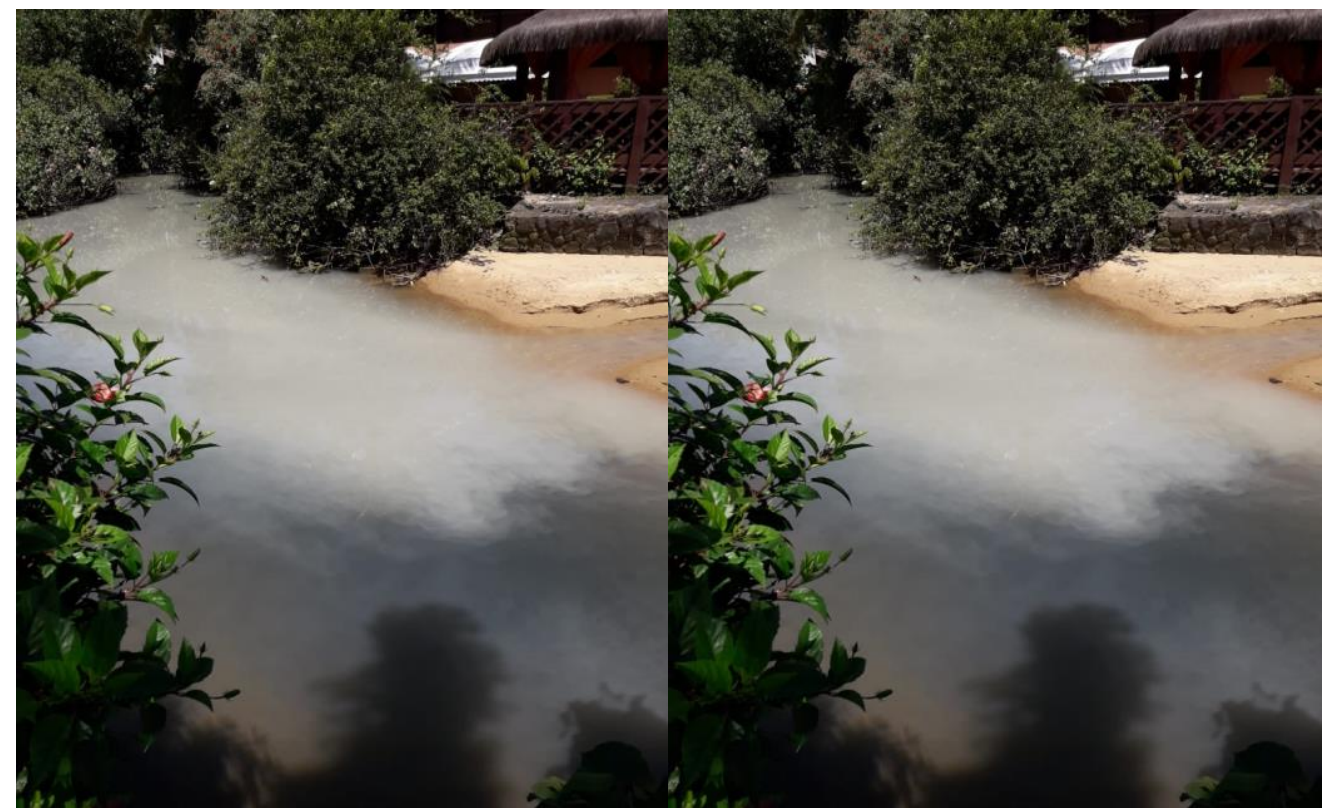

Figura 2:Rio que liga o mar, com coloração branca para azul

Figure 2: River that connects the sea, with blue and white color

Fonte: Eduardo Gouvea (2018).

Source: Eduardo Gouvea (2018).

Segundo relato do gestor do parque, os funcionários do Parque seguiram o rastro pela cor da água subindo o rio e chegaram até uma pousada onde foi constatada, após vistoria, que o estabelecimento não é ligado à rede de esgoto e não possuía fossa, ou seja, todo líquido de banheiro e cozinha estava escoando diretamente para o rio.

Essa poluição também é visível para alguns turistas, pois alguns deles fizeram os seguintes relatos: "não tem preocupação com a preservação ambiental, pensam só no dinheiro do turismo", "efluentes e dejetos (de todos), é visível a poluição dos rios, choveu por 3 dias na llha", "Vi do restaurante, desce uma vala preta".

A questão dos efluentes domésticos como consequência da carência da gestão costeira, com a interdição da obra da ETE, que atualmente não trata toda demanda de esgoto, aliado à falta de consciência ambiental por parte de alguns entrevistados é evidente na praia do Abraão. Esse cenário acarreta impactos negativos na qualidade física e biológica do ambiente marinho e na paisagem cênica. Inevitavelmente o declínio da atividade turística ocorrerá e, consequentemente, a desvalorização da llha Grande como roteiro turístico.

Continuando a análise exploratória sobre os esgotos domésticos pela Ilha Grande, a praia do Aventureiro, onde predominam o sistema de fossas e/ou sumidouros. Durante o trabalho de campo realizado em dezembro de 2018, foi possível observar a cor escura e o cheiro semelhante ao esgoto de uma das barras escoando para o mar. Andando pela praia nota-se o início de um novo córrego saindo da casa de um dos moradores com a água escura, que era visível para todos que passavam. 
Já em janeiro de 2019, foi registrado um pequeno córrego com coloração esverdeada, onde era possível visualizar uma floração de algas, que é formada pelo acúmulo de nutrientes, na maioria das vezes provenientes de esgoto doméstico (Figura 3).

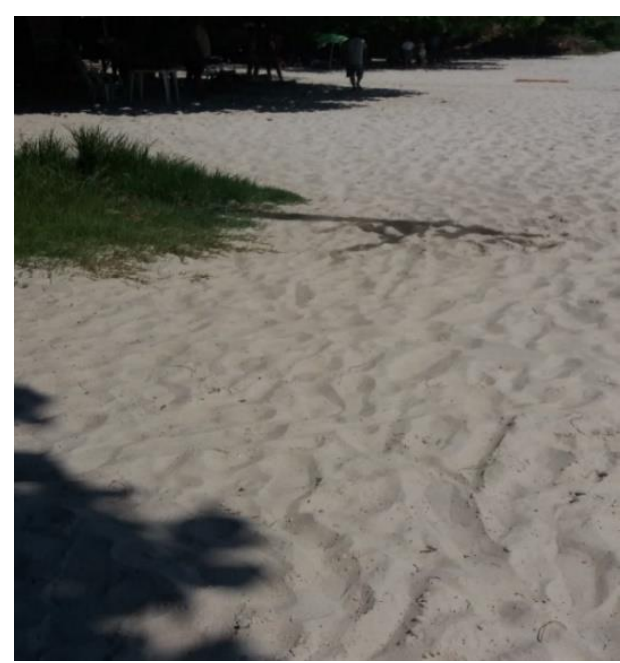

Figura 3: Início do efluente.

Figure 3: The beginning of the effluent.

Fonte: Chueiri (2019).

Source: Chueiri (2019).

Após uma semana, foi tirada outra foto do mesmo local, só que dessa vez, a foto foi feita do mirante do Sundara, pelo qual é possível ver toda extensão da praia do Aventureiro. O mesmo córrego retratado acima, que antes era pequeno, dessa vez se estendia até o mar (Figura 4).

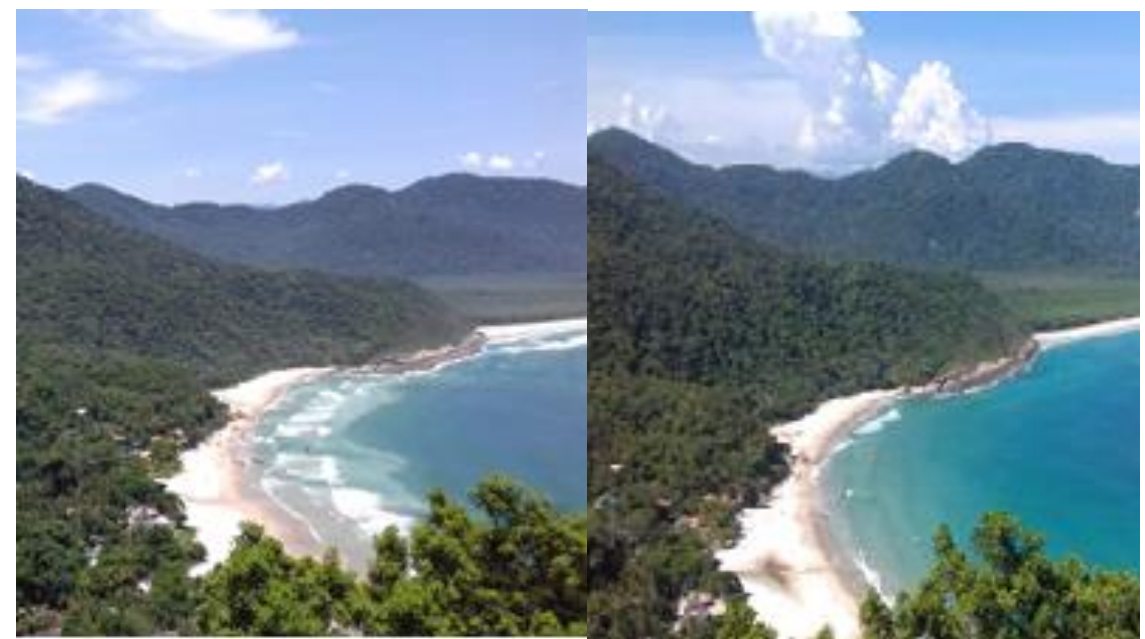

Figura 4: Vista do mirante do Sundara, com o início do córrego (lado direito ) e com a evolução do lado esquerdo.

Figure 4: View from the Sundara viewpoint, with the beginning of the stream (right side) and with the evolution on the left side

Fonte: Chueiri (2019).

Source: Chueiri (2019). 
Com a chegada da alta temporada em janeiro de 2019, segundo relatos de moradores, aproximadamente duas mil pessoas visitaram a praia do Aventureiro. Esse número excedeu a capacidade estrutural do Aventureiro, deixando marcas de poluição pelos córregos que desaguam no mar (Figura 5).

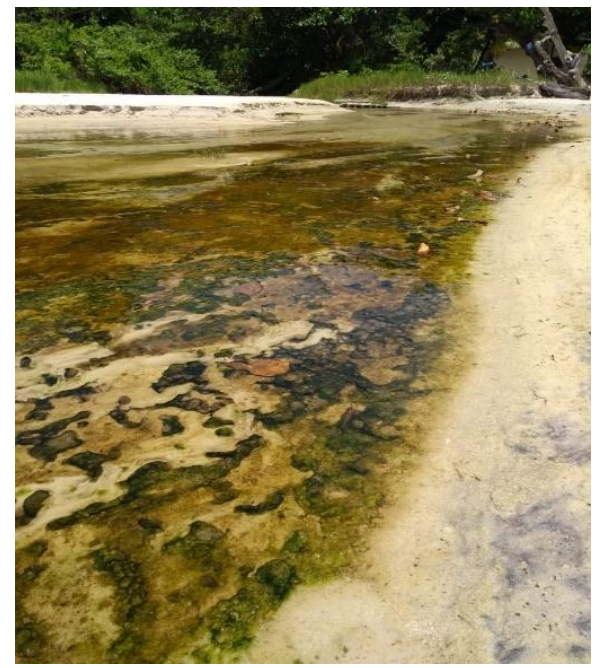

Figura 5: poluição do córrego.

Figura 5: stream pollution.

Fonte: Chueiri (2019).

Source: Chueiri (2019).

Segundo relatos de moradores, grande parte da poluição por esgoto doméstico na praia do Aventureiro é proveniente da água da pia, do chuveiro e até de gordura. Algumas propriedades não possuem caixa de gordura.

Os turistas percebiam a coloração e o cheiro ruim das valas, uma entrevistada afirma ter visto uma água saindo do camping que estava com cheiro ruim e coloração escura. No entanto, parte dos moradores parece não se preocupar com tal situação, dizendo que é normal, ressaltando que "como é mar aberto, não tem problema" e que todo ano é a mesma coisa na alta temporada.

Apesar do turismo ser a principal fonte de renda para a população local, a consciência de que a própria natureza está demonstrando a saturação de absorção não é reconhecida por alguns dos moradores.

O problema dos efluentes como uma consequência da falta de gestão costeira na praia do Aventureiro, ao mesmo tempo que é grave pela falta de saneamento básico, o fato dela estar localizada em mar aberto leva algumas pessoas a acreditarem que o ambiente não está poluído por conta da circulação das correntes e marés.

Por outro lado, alguns moradores alegam que o lançamento dos esgotos é o maior problema da praia do Aventureiro e tentam minimizar esses problemas misturando água com os efluentes para diluir antes que chegue ao mar e plantando bananeiras na saída dos efluentes para filtrar antes de jogar direto para o mar. 


\section{Considerações finais}

É notória que existe uma diferença quanto a intensidade dos impactos negativos voltado para o mar entre Abraão e Aventureiro, proveniente do despejo de esgoto doméstico. Porém a falta de consciência ambiental por parte de alguns entrevistados é comum entre as duas praias.

A maior parte da vila de Abraão está dentro da Reserva de Tamoios, APA, que é administrado pela prefeitura de Angra, e não faz um controle de entrada de turistas e moradores. $O$ acesso para a vila é relativamente fácil, apresentando um grande número de embarcações regulares, além dos táxis boat.

Em relação à cadeia produtiva do turismo tradicional, a vila de Abraão possui uma infraestrutura boa, porém quando pensada sob a ótica da gestão costeira, ela se torna precária, devido à ineficiência do saneamento básico.

Já Aventureiro está inserido na (RDS), administrada pelo INEA, onde as leis ambientais são rígidas, controlando novas construções e reformas, proibindo a venda de terrenos e casas, dentre outros. Existe também um controle oficial da capacidade de suporte feito pela TURISANGRA, mas não é bem organizado e fiscalizado.

O acesso para Aventureiro é mais complicado por ser mar aberto, distante do continente e não tem embarcações regulares. Possui uma infraestrutura ruim, se considerados os termos das exigências do turismo convencional, pois todos os empreendimentos são nos quintais da casa dos moradores e, de acordo com eles, "as casas não possuem fossa, apenas sumidouros".

Após a realização deste estudo, pode-se afirmar que a falta de um plano de gestão costeira é evidente nas duas praias. É possível dizer que a vila de Abraão já perdeu o controle quanto ao desenvolvimento ordenado do turismo e que Aventureiro, mesmo sendo uma RDS, já mostra indícios de poluição. Em aventureiro ficou claro que o pensamento é: o mar é aberto, então "não tem problema, não polui". Já em Abraão, o pensamento de alguns é pautado na ação de jogar os resíduos sólidos e líquidos diretamente ou indiretamente no mar, tendo em vista, que está comprovado por análises físico-químico e microbiológico que a praia principal, Abraão, está imprópria para banho.

O turismo aparece como sinônimo de tensão e, ao mesmo tempo, de lazer e de oportunidade na Ilha Grande. Por um lado, as pessoas usufruem das belezas naturais e os moradores tentam sobreviver da renda oriunda do turismo, por outro lado, o fluxo descontrolado de pessoas degradam o ambiente e produz conflitos socioambientais.

Nesse cenário, a gestão costeira se apresenta como um instrumento para minimizar tais conflitos, propondo uma coleta adequada dos esgotos domésticos e tratamento direcionado para cada tipo de efluente, de acordo com a legislação ambiental vigente. 
A falta de uma gestão costeira poderá ocasionar não apenas a contaminação das águas superficiais, como já ocorre na Vila de Abrão, mas também das águas subterrâneas. A gestão costeira precisa ser aplicada com maior rigor para garantir a sustentabilidade social, econômica e ambiental da Ilha Grande como um importante destino turístico do litoral brasileiro.

\section{Notas:}

1 Período de gestão fevereiro de 2017 até janeiro de 2019

\section{Agradecimentos}

A Coordenação de Aperfeiçoamento de Pessoal de Nível Superior CAPES, pelo financiamento da bolsa de estudo da primeira autora do artigo;

Ao programa de Pós Graduação Multidisciplinar em Meio Ambiente da Universidade Estadual do Rio de Janeiro PPGMA/UERJ, pelo apoio financeiro referente as diárias de campo;

Ao Instituto Estadual do Ambiente do estado do Rio de Janeiro INEA, polo situado na llha Grande, pelo fornecimento das informações institucionais, incluindo entrevistas e materiais institucionais e por ceder 0 alojamento de pesquisadores no período do campo.

Ao estagiário e aluno Felipe Lage, do curso de graduação da oceanografia, da Universidade Estadual do Rio de Janeiro, pelo suporte na saída de campo.

\section{Referências}

ARAUJO, C. D.; CARVALHO, A. G.; SILVA, C. D. Impactos ambientais do Turismo na Ilha Grande: Um estudo Comparativo sobre a percepção dos moradores da Vila do Abraão e da Vila Dois Rios. Caderno Virtual de Turismo, v. 5, p. 9, 2005.

BRASIL. Lei n. 9.985, de 18 de junho de 2000. Regulamenta o art. 225, § 1으, incisos I, II, III e VII da Constituição Federal, institui o Sistema Nacional de Unidades de Conservação da Natureza e dá outras providências. Disponível

em:<http://alerjln1.alerj.rj.gov.br/constfed.nsf/16adba33b2e5149e032568f600 71600f/62e3ee4d23ca92ca0325656200708dde?OpenDocument> Acesso em: 15 nov. 2019.

BRIGUGLIO, L.; BRIGUGLIO, M. Sustainable tourism in small islands. In: Sustainable Tourism in Islands and Small States: Issues and Policies. London: Cassell/Pinter, 1996. p. 317.

CONAMA. Conselho Nacional Do Meio Ambiente (Brasil) -: Resolução nº. 274 , de 29 de novembro de 2000. Define os critérios de balneabilidade em águas brasileiras. Disponível em: <https://cetesb.sp.gov.br/aguasinteriores/wpcontent/uploads/sites/12/2018/01/RESOLU\%C3\%87\%C3\%83O-CONAMAn\%C2\%BA-274-de-29-de-novembro-de-2000.pdf> Acesso em: 15 nov. 2019 
CREED, J. C.; OLIVEIRA, A. E. S. Uma Metodologia e Análise de Impactos Ambientais. In: CREED, J. C.; PIRES, D. O. P.; FIGUEIREDO, M. A. O. (Eds.). Biodiversidade Marinha da Baía da llha Grande. Brasília: Ministério do Meio Ambiente, 2007. p. 75-108.

DIEGUES, A. C. Human populations and coastal wetlands: Conservation and management in Brazil. Ocean and Coastal Management, v. 42, n. 2-4, p. 187-210, 1 fev. 1999.

IBGE. INSTITUTO BRASILEIRO DE GEOGRAFIA E ESTATISTICA. Atlas geográfico das zonas costeiras e oceânicas do Brasil. Rio de Janeiro: IBGE, 2011. p.176.

INEA. INSTITUTO ESTADUAL DO AMBIENTE. Plano de Manejo (fase 2): Parque Estadual da Ilha Grande - PEIG. Disponível em: <http://www.inea.rj.gov.br/cs/groups/public/documents/document/bmvh/mdey / edisp/inea012819.pdf>. Acesso em: 11 mar. 2019.

INEA. Instituto Estadual Do Ambiente - INEA: Histórico anual de Balneabilidade, Ilha Grande (2008 - 2015). Disponível em: $<$ <ttp://www.inea.rj.gov.br/Portal/MegaDropDown/Monitoramento/Qualidaded aagua/Praias/BalneabilidadeporMunicpio/AngradosReis/llhaGrande/index.ht m\&lang=\#/Descricao $>$. Acesso em: 18 jan, 2019.

JOHNSSON, R. M. F.; IKEMOTO, S. Diagnóstico do setor costeiro da Baía da Ilha Grande: Subsídios à elaboração do zoneamento ecológicoeconômico costeiro. Rio de Janeiro: Instituto Estadual do Ambiente, 2015.

LINS-DE-BARROS, F. M.; MANSUR, K. L. Desafios da gestão costeira integrada da Região dos Lagos (RJ): uma análise baseada na vulnerabilidade costeira e nos serviços ecossistêmicos da geodiversidade. Revista Brasileira de Geografia, v. 63, n. 1, p. 73-97, 2018.

MARQUES JR., A. N.; MORAES DE, R. B. C.; MAURAT, M. C. Poluição Marinha. In: PEREIRA, R. C.; SOARES-GOMES, A. (Eds.). Biologia Marinha. 2.ed. Rio de Janeiro: Interciência, p. 505-526, 2009.

MEDEIROS, E. C. S.; MAIA, L. P.; PEREIRA DE ARAÚJO, R. C. Capacidade de carga de uma praia sob o impacto do processo de erosao costeira (praia do Icaraí). Subsídios para o gerenciamento costeiro do estado do Ceará, Brasil. Journal of Integrated Coastal Zone Management, v. 16, n. 2, p. 185-193, 2016.

MENDONÇA, T. C. M.; FONTOURA, L. M. Meu lugar virou reserva biológica e paraíso para turistas: restrições, conflitos e possibilidades. Anais do $\mathrm{V}$ Encontro Nacional da Anppas 4 a 7 de outubro de 2010 Florianópolis - SC Brasil, 2010.

MENDONÇA, T. C. M.; MORAES, E. A. O povo de aventureiro e o Turismo de Base Comunitária. Rio de Janeiro: Ed. da UFRRJ, 2011. p. 218.

MORAES, A. C. R. Contribuições para a gestão da zona costeira do Brasil: Elementos para a geografia do litoral brasileiro. São Paulo: Hucitec, 1999. 
NICOLODI, J. L.; ZAMBONI, A.; BARROSO, G. F. Gestão Integrada de Bacias Hidrográficas e Zonas Costeiras no Brasil: Implicações para a Região Hidrográfica Amazônica. Revista da Gestão Costeira Integrada, v. 9, n. 2, p. 9-32, 2009.

OLIVEIRA, T. C. R. DE et al. Classificação dos cenários costeiros de praias da Ilha de Santa Catarina, Florianópolis - Brasil. Desenvolvimento e Meio Ambiente, v. 39, p. 217-229, 2016.

PIRES, A. Fluxo Turístico Ilha Grande [mensagem pessoal]. Mensagem recebida por <tur.ccitu@angra.rj.gov.br> em 07 jun. 2019.

POLETTE, M. et al. Gerenciamento Costeiro Integrado e Gerenciamento de Recursos Hídricos: Como Compatibilizar Tal Desafio. In: MUÑOZ, H. R. (Ed.). Interfaces da gestão de recursos hídricos: desafios da Lei de Águas de 1997. 2. ed. Brasília: Ministério do Meio Ambiente. Secretaria de Recursos Hídricos, 2000. p. 221-239.

POLETTE, M.; SILVA, L. P. GESAMP, ICAM e PNGC: análise comparativa entre as metodologias de gerenciamento costeiro integrado. Ciência e Cultura, v. 55, n. 4, p. 27-31, 2003.

RIO DE JANEIRO. Decreto No 20.172, de 01 de julho de 1994. Institui o Plano Diretor da Área de Proteção Ambiental de Tamoios, localizada no Município de Angra dos Reis, criada pelo Decreto № 9.452, de 05/12/86. Disponível

em:<http://www.angra.rj.gov.br/sapo/_uploads/SAD/doc/concurso/Decreto_e statual_20172_94.htm> Acesso em: 15 jan. 2019.

SILVA JUNIOR, L. et al. A qualidade visual da paisagem do Parque Estadual da llha Anchieta, Ubatuba (SP). Revista Brasileira de Ecoturismo (RBEcotur), v. 9, n. 2, p. 318-345, 2016.

VILAÇA, A. M.; MAIA, Â. DE A. O povo de Aventureiro. In: PRADO, R. . (Ed.). Ilha Grande: do sambaqui ao turismo. Rio de Janeiro: Garamond/EDUERJ, 2006. p. 59-104.

WILSON, O. E. The Diversity of Life. New York: W.W.Norton \& Company, 1999.

WUNDER, S. Modelos de Turismo, florestas e rendas locais. In: PRADO, R. (Ed.). Ilha Grande: do sambaqui ao turismo. Rio de Janeiro: Garamond/EDUERJ, 2006. p. 133-190. 
Débora Mury Alves Chueiri: Universidade Estadual do Rio de Janeiro, Rio de Janeiro, RJ, Brasil.

E-mail: deboramury10@gmail.com

Link para o currículo Lattes: http://lattes.cnpq.br/8438755417209250

Rafael Angelo Fortunato: Universidade Estadual do Rio de Janeiro, Rio de Janeiro, RJ, Brasil.

E-mail: fortrafa@hotmail.com

Link para o currículo Lattes: http://lattes.cnpq.br/8616988019237581

Data de submissão: 10 de junho de 2020

Data de recebimento de correções: 16 de junho de 2020

Data do aceite: 16 de junho de 2020

Avaliado anonimamente 